\title{
Concept of the educational cluster creating in the field of construction industry
}

\author{
Alina Chernobrovina ${ }^{1, *}$, Lada Shehovtsova ${ }^{1}$, and Dmitriy Oboznyiy ${ }^{1}$ \\ ${ }^{1}$ Novosibirsk State University of Architecture and Civil Engineering, Novosibirsk, 630008,Russia
}

\begin{abstract}
The implementation of modern requirements for the experts' competence of construction industry requires active cooperation between educational institutions and industry. The educational cluster in the field of experts training for the regional construction industry is considered as an effective mechanism for this interaction implementation in the article. The concept of the educational cluster creating involves its main members, identifying their roles and key steps to create this cluster. The importance of the educational cluster project confirms the predicted number of positive effects from its inception to the region's economy, building firms, educational institutions of secondary and higher vocational education.
\end{abstract}

\section{Introduction}

Currently, a necessary reason for the successful development of the higher education system and education quality improving is the effective cooperation of higher education institutions and firms-employers. Educational programs focused on the labor market, have become a major indicator of higher education quality and its effectiveness. A significant prerequisite for today is the active cooperation of educational institutions and employers, formation of the necessary requirements and criteria for graduates [1].

Foreign experience of educational clusters reveals that the clusters have opportunities to further stimulation, and significantly improve the quality of education and innovation in the whole educational process [2] Different industries representatives have come to realize the need of interaction improving between universities and enterprises in the framework of the cluster approach. The lack of such interaction leads to distortions in the construction labor market and the education market.

An important organizational and methodological challenge of the cluster approach application is to create a concept of education cluster and determining the interaction of its member's mechanisms.

The term "cluster" was introduced by the American economist Michael Porter in 1990. M. Porter [3] considers the cluster as a group of geographically adjacent interconnected companies and associated organizations, operating in a certain area and complementing each other. Members of the cluster must be on the same territory, which facilitates communication and allows realizing synergies from this interaction.

*Corresponding author: chernobrovina@inbox.ru 
L. Yang [4] points in his definition on a cluster's companies - participants, which should be located near major universities, so it allows professionals training with the appropriate skills and competence for successful work in these companies. Thus, it becomes clear that the system integrator of the cluster is to be a leading university in the industry.

E.A. Monastyrskii [5] underlines the importance of scientific knowledge generating in a cluster that allows producing a product with a long-term competitive advantages.

The result of the cluster activities is its product creation. The final result of the cluster activity in any education system is to prepare the required quality graduates with competencies which can satisfy employers as the educational process participants [6]. Studying educational cluster, we consider highly skilled experts and construction industry innovations as final products.

A group of authors with a head of I.E. Vildanov [7] consider the educational cluster as a way of bringing research stakeholders together in the same field and training at all educational levels: secondary, higher education, continuing professional education.

The emphasis on teaching component of the educational cluster is given in the dictionary definition, "Russian Corporation of Nanotechnologies", "Education Cluster educational system, mutual learning and self-learning tools in the innovation chain" science - technology - business "is based mainly on horizontal relationships within the chain" [ 8].

L.D. Medvedeva and I.Y. Malikova [9] emphasize the need for public-private partnership in the education cluster, thanks to which there is a possibility to organize an interaction between educational institutions, businesses and government power of professional education management in a region.

P.D. Shimko underlined in his definition, that it is possible to implement the principles of continuing education in the education cluster. He defines the educational cluster as a network of regional integration formation, including related educational institutions of different levels, combined orientation and continuity of educational training programs, partnerships with companies, research organizations, and executive authorities [10].

Terminological analysis allows us to formulate the following definition of the educational cluster in the constructional sphere. The educational cluster in the field of construction is a modern scientific and educational complex of interconnected scientific organizations and educational institutions (secondary, higher and secondary vocational education) in the field of construction, with strong partnerships with construction industry companies, as well as with local authorities.

\section{Research}

The research work on the education cluster creation in the field of highly skilled construction experts' preparation in the Novosibirsk region has been conducted from April 2016. The initiative of educational cluster creating belongs to the Novosibirsk State University of Architecture and Civil Engineering (Sibstrin) and the Government of the Novosibirsk region.

Industrial university [11] is worthwhile to consider as the cluster core. In our work it is Novosibirsk State University of Architecture and Civil Engineering (Sibstrin), the oldest university, founded in 1930. The University is considered as the main supplier of highly qualified personnel for the Novosibirsk region construction industry. The University has a wealth of experience in effective educational programs development and implementation, including corporate training, extensive use of advanced educational technologies. The innovative and educational center was created in the university. New mechanisms to adapt educational process of production demands on the basis of integration, cooperation and social responsibility are created in this center. 
This created educational cluster can be represented as a structure of mutually cooperate following systems: business, education and science, government and industry. A cluster is a kind of round table where representatives of business, education and science, the authorities are able to solve common problems, relating to innovative development of the Novosibirsk region construction industry (see Figure 1).

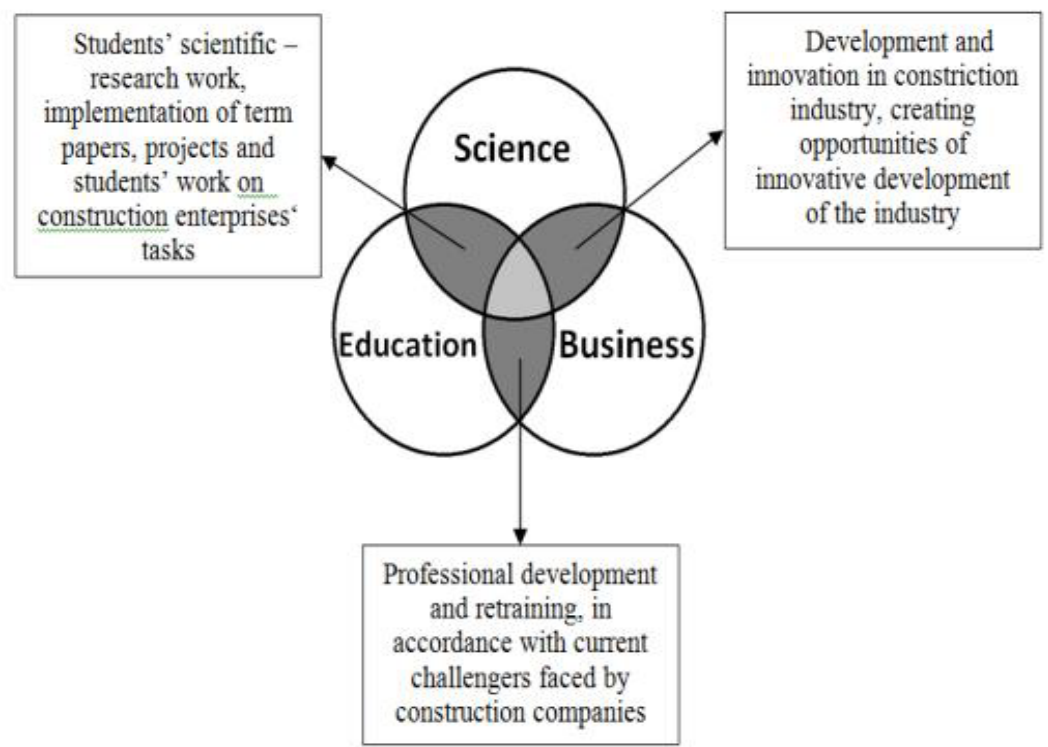

Fig. 1. Interaction of construction business, education and science in building-construction educational cluster.

Cluster structure comprises four main blocks: training and education, research and development, production and executive power [12].

The training and education unit includes educational institutions engaging in specialists training in the field of construction industry: Novosibirsk State University of Architecture and Civil Engineering (Sibstrin) as a higher educational institution, three professional colleges, a number of secondary schools with engineering classes. In addition to the professional educational institutions, the cluster consists of several secondary schools. Attracting students will allow them to choose the profession more quickly and more consciously [13]. Also there is an educational effect, which manifests itself in improving the general cultural level of students, thanks to universities attaching to the academic environment.

Research unit brings together organizations, engaged in research work in the field of construction technology, new materials, designs, and modern software introduction. Students of educational organizations within the cluster have the opportunity during training to engage in research on modern equipment.

The manufacturing unit includes the largest constriction corporations of the region, as well as manufacturers of building materials and structures.

Executive power authorities are presented by Industrial Ministries, regulating the construction industry, housing and communal services and the education system of the Novosibirsk region.

Creation of the educational cluster process contains the following key steps:

1. Development of mechanism of the educational cluster formation:

- identification of cluster's potential participants. They should be interested in mutually beneficial relations establishing; 
- determination of the cluster's principles of functioning: target participants, overall strategic goal, development strategy;

- identify the relationships and interdependencies within the cluster;

- development of regulations, rules and regulations to ensure the cluster functioning.

2. Create the cluster management structure and mechanism of functioning:

- determination of the Coordinating Council members;

- Formation of committees;

- definition of the functional responsibilities of cluster members;

- determination of cluster members' joint activities.

3. Evaluation and selection of priority directions of the educational cluster development, taking in account:

- Development Strategy of the Novosibirsk region;

- Development Strategy of the Novosibirsk Region building complex;

- target parameters of cluster activities, identified by the Ministry of Education and Science of Russia.

\section{Results}

Expected project results of the educational cluster creation are realization of a number of positive effects for all members of the cluster and regional economy as a whole [14]. Further, we consider the way, how educational cluster will affect on its key players.

The positive effects on society and the region:

1. Raising the prestige of building profession and engineering professions. Involve young people in the construction industry activity.

2. Preparation of highly qualified experts for implementation of economic development programs in the region.

3. Eliminating inconsistencies of labor market and education market. [15]

The positive effects for the construction industry:

1. Preparation of qualified young specialists who are able to adapt to the work in a construction company immediately. Train young specialists together with enterprise staff.

2. Create a flexible system of enterprises staff professional development, taking into account current and expected production requirements. Employees of the companies have an opportunity to learn (to develop their professional skills, to receive additional education) in the workplace and the right to convert acquired knowledge and skills in the work experience, thereby increasing their effectiveness.

3. Professional development program can be linked to the company's strategy that allows workers to increase competitiveness of building organizations.

4. Close cooperation with research institutions enables to develop and introduce various innovations (organizational, technical, technological, information, management). Direct connection between science and education allows workers to link educational programs with innovative developments.

5. Organization of scientific and information service of enterprises workers.

Positive effects for educational institutions:

1. Sponsorship with meeting rooms and equipment. Development of practice of enterprises chairs creating.

2. The presence of a permanent services market (education, research, consulting, design, etc.).

3. Elimination of university teaching isolation from modern construction industry requirements, including inconsistency of educational and material-technical base of institutions with modern production technology. 
4. Working out educational programs with the needs and the development strategy of building complex, including by attracting highly skilled staff in the educational process.

5. Formation of a stable students staff (to attract the most prepared and talented youth in the architectural and constriction university) by the raising of construction industry prestige and employment guarantees.

6. Ensuring the continuity of educational programs levels through educational institutions interaction of higher and secondary vocational education.

7. Perform SRED developments on the subjects, connected with enterprises experience on the basis of economic contracts and agreements on creative collaboration.

The positive effects for students of educational institutions:

1. Gain necessary skills and knowledge for the really work; it'll reduce the process of adaptation students to the working activity [16].

2. Provide students with jobs in laboratories, workshops, production facilities for performance of all kinds of educational and research activities, as well as for passage of industrial practice.

An important result of experts training in the education cluster is to improve the quality of education, as a basic vocational and additional. The quality of teaching in higher and professional organizations is check by the government (Ministry of Education and Science of Russia), by monitoring compliance with federal education standards, licensing of educational organization and accreditation of educational programs. However, it does not control the quality of additional professional education. Now every Russian region has dozens of training centers and certification in the field of construction industry. The base of their educational activity is only presence of the license for conducting it. However, the licensing authority is not responsible for the results and quality of these organizations work.

It is possible to create a Regional Accreditation Agency, which will monitor the quality of additional professional development in the education cluster. The functions of the agency are: evaluation of educational institutions programs' quality in the field of construction industry, applying for accreditation; participate in the professional standards development and qualification characteristics; development of educational recommendations (teaching aids) and methodological support for the retraining and advanced training industry.

\section{Conclusion}

Construction industry experience shows it is very difficult to get the production and economic benefit, even with sufficient financial means and expensive equipment, but without an adequate level of specialists' preparation. The proposed concept of the educational cluster allows us to support the efforts for the formation and implementation of personnel policy in the sphere of construction industry: creation and development of human resources as the most important intellectual and professional resources for economic development. The educational cluster creating in the region construction industry will allow solving the complex issue of staff training, retraining and advanced training.

\section{References}

1. M.V. Lychagin, L.V. Shekhovtsova. SAFBD1, 284-287 (2011)

2. E.A. Kurnosova, Russian economic internet-journal 1, 598-607 (2009)

3. M. Porter, Competition Williams, 592 (2010)

4. L.E. Young, Technology parks and clusters of firms (2005)

5. E.A. Monastyrskii, Innovation Publ. 5, 38-43 (2006) 
6. M.V. Goldobin Education Cluster9-2 (131), 114-120 (2015)

7. I.E. Vildanov, R.S. Safin, E.A. Korchagin R.N. Abitov, Kazan pedagogical journal1 (102), 44-53 (2014)

8. Nanotechnology Dictionary, http: // www.rusnano.com

9. L.D. Medvedev, I.Y. Malkov, Scientific and pedagogical review1(11), 58-63 (2016)

10. P.D. Shimko, Economics of Education 4, 57-72 (2009)

11. A.B. Chernobrovina, Siberian Branch-set,108-114 (2009)

12. T.V. Sidorina, L.V. Shekhovtsova, A.B. Chernobrovina, Proceedings of the 10th international academic conference, 85-93 (2016)

13. L.V. Shekhovtsov, G.N. Anufrieva, Siberian Academy of Finance and Banking, 121127 (2009)

14. T.V. Sidorina, L.V. Shekhovtsova, A.B. Chernobrovina, Achievements and Perspectives 11th International symposium, 31-35 (2016)

15. A.A. Emelyanovich, E.A. Kulyagina, Transport case Russia5, 42-43(2016)

16. L.V. Shekhovtsov, International scientific-practical conference, 342-346 (2014) 